\title{
Duodenal hematoma following endoscopic duodenal biopsy: A case report and review of the literature
}

\author{
Daniel R Diniz-Santos MD¹, Romilda C de Andrade Cairo MD ${ }^{1}$, Hélio Braga MD², Cesar Araújo-Neto MD², \\ Igelmar B Paes $\mathrm{MD}^{3}$, Luciana R Silva MD PhD ${ }^{1}$
}

\begin{abstract}
DR Diniz-Santos, RC de Andrade Cairo, H Braga, C Araújo-Neto, IB Paes, LR Silva. Duodenal hematoma following endoscopic duodenal biopsy: A case report and review of the literature. Can J Gastroenterol 2006;20(1):39-42.

Duodenal hematoma is a rare complication of endoscopic duodenal biopsy that occurs mainly in children or adults with impaired coagulation. The clinical presentation consists of signs of intestinal obstruction, and pancreatitis and direct hyperbilirubinemia are possible complications caused by ampullary obstruction. A case of a sixyear-old girl who presented with a duodenal hematoma and acute pancreatitis after having an endoscopic duodenal biopsy is reported. A review of the literature and data from all similar cases reported so far are briefly presented and discussed.
\end{abstract}

\section{Un hématome duodénal après une biopsie duodénale par endoscopie : Rapport de cas et analyse bibliographique}

Key Words: Biopsy; Duodenal hematoma; Endoscopy; Pancreatitis

\begin{abstract}
A lthough acute pancreatitis is a well-described complication of endoscopic retrograde cholangiopancreatography (1), it is such a rare complication of upper gastrointestinal endoscopy that most reviews addressing such events simply mention this possible adverse outcome and refer to a few case reports (2-4). The link between upper gastrointestinal endoscopy, a safe procedure with a very low rate of complications, and acute pancreatitis, a severe life-threatening condition, is duodenal hematoma, an uncommon complication of abdominal trauma in children (5) that is very rarely related to endoscopic duodenal biopsy.

Duodenal hematomas may be caused by a crushing force, which forces the intestine against the vertebrae, or by a shearing force, which may rupture intramural blood vessels. When bleeding occurs, it may be either intraluminal or intramural. Intraluminal bleeding is not associated with important complications unless the hemorrhage is severe enough to interfere with hemodynamics. Intramural bleeding, however, leads to intramural accumulation of blood, resulting in a hematoma that is further enhanced by an osmotic fluid shift from the surrounding environment, forming an intraluminal bulge that may lead to duodenal occlusion. Furthermore, intramural duodenal hematoma can compress adjacent structures (eg, pancreatic and biliary ducts), causing obstructive jaundice or acute pancreatitis. Interestingly, duodenal hematoma after duodenal biopsy has been noted mainly among infants and young adults and has not been clearly associated with any risk factor (6), even though a significant number of the cases reported so far
\end{abstract}

occurred in patients with blood dyscrasia or under anticoagulant therapy (7-9).

\section{CASE PRESENTATION}

A six-year-old girl with no relevant medical history and complaining of upper abdominal tenderness for six months underwent a diagnostic upper gastrointestinal endoscopy with duodenal biopsy. She had no history of acetylsalicylic acid or nonsteroidal anti-inflamatory drug use, and no familial history of blood dyscrasia.

There was no difficulty in performing the endoscopy. The patient received intravenous propofol and tolerated the procedure well. The endoscope was easily passed to the second portion of the duodenum, where two biopsy specimens were obtained for histological assessment with grasp forceps (Pentax KW1815S, Pentax Inc, Japan). Several points of hemorrhagic gastritis were seen on the antrum and were also biopsied. No excessive bleeding was noted from the biopsy sites and there was no evidence of vascular malformation at the stomach or duodenum. Helicobacter pylori infection or histological abnormality was not detected on the antral biopsy specimens, and the duodenal biopsies were normal. Intravenous omeprazole was started.

Two hours after the endoscopy, the patient presented with intense, diffuse, abdominal tenderness and heavy, persistent vomiting. Biochemical evaluation revealed hyperamylasemia $(527 \mathrm{U} / \mathrm{L})$ and hyperlipasemia $(10,196 \mathrm{U} / \mathrm{L})$. The hemoglobin was $125 \mathrm{~g} / \mathrm{L}$, white cell count was $14.6 \times 10^{9} / \mathrm{L}$, prothrombin time was $15.1 \mathrm{~s}$ (international normalized ratio of 1.08),

${ }^{1}$ Division of Pediatric Gastroenterology and Hepatology, Professor Hosannah Oliveira Pediatric Center, Federal University of Bahia; ${ }^{2}$ Division of Radiology, Hospital Aliança; ${ }^{3}$ Division of Digestive Endoscopy, Hospital Aliança, Salvador, Brazil

Correspondence: Dr Daniel R Diniz-Santos, Av Princesa Isabel, 549, apt 11, Barra Avenida, Salvador, Bahia, Brazil, CEP: $40130-030$.

Telephone and fax 55-71-32-64-44-24, e-mail danieldiniz82@ig.com.br 


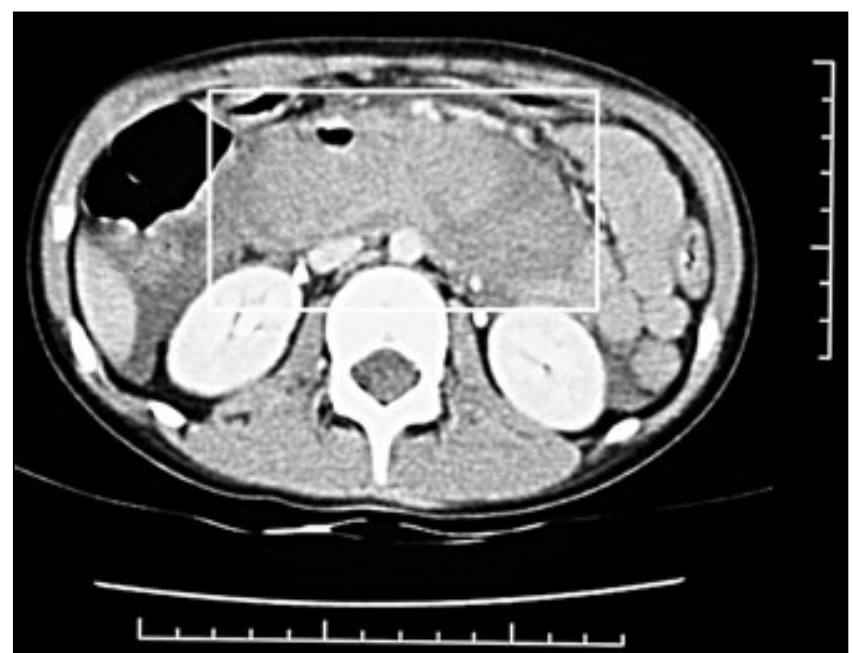

Figure 1) Duodenal hematoma. Contrast-enhanced computed tomogram showing a large heterogeneous hyperdense mass within the second through fourth portions of the duodenum (box)

platelets $279 \times 10^{9} / \mathrm{L}$ and lactate dehydrogenase $705 \mathrm{U} / \mathrm{L}$. Blood glucose, electrolytes, aminotransferases, bilirubin and other liver function tests were within normal limits. Computed tomography (CT) with intravenous contrast performed on day 2 revealed an asymmetric mass compatible with a hematoma on the second through fourth duodenal portions, along with edematous acute pancreatitis, free fluid on the abdominal cavity and no signs of bowel perforation (Figure 1). A new endoscopy was performed to assess the extent of duodenal occlusion and it showed two large intramural hematomas bulging into the duodenum, one of them completely blocking the lumen. Because no perforation had been detected, the patient was managed conservatively.

Subsequently, amylase and lipase concentrations decreased steadily. Upper abdominal magnetic resonance (MR) performed on day 8 indicated significant reduction of the duodenal hematoma. By day 10, the patient reported relief of the abdominal pain and the hematoma had resolved, as indicated by the return of clear liquid through the nasogastric tube. Gradual transition to oral feeding was restarted with good results, and parenteral nutrition was interrupted at day 15 . A new MR scan showed ultimate resolution of the duodenal hematoma and reduction of the pancreatic head.

The patient was discharged on day 19 without any complaint and was instructed to continue therapy with oral omeprazole. No other episodes of melena were detected in the hospital or after discharge. Fifteen days after discharge, a new biochemical evaluation showed normal amylase and lipase, and a new MR scan was normal, not showing any encapsulated peripancreatic collection (pseudocyst). The omeprazole was discontinued after eight weeks, and the patient was still asymptomatic 18 months later.

\section{DISCUSSION}

We presented the case of a six-year-old girl with peptic ulcer disease who developed an intramural duodenal hematoma following an endoscopic duodenal biopsy. She was successfully treated conservatively. Interestingly, she had none of the wellknown risk factors for peptic ulcer disease and duodenal hematomas, which may suggest that her coagulation was somehow impaired due to an unknown cause, such as a platelet function disturbance.

Most problems during pediatric nontherapeutic endoscopies are somehow related to sedation, but bleeding, perforation and infectious complications have also been reported (2-4). Following nontherapeutic endoscopy, very few patients experience major discomfort signs such as vomiting, which is more commonly a side effect of the intravenous sedative agents and is usually mild and subsides within a few hours of sleep.

In our review of the literature, we found that this is the 18th case of intramural duodenal hematoma following endoscopic duodenal biopsy to be reported (Table 1).

Of the 18 similar cases reported in the literature, 13 (72.2\%) happened in patients younger than 21 years; four of the remaining five nonpediatric patients had impaired coagulation and the other had a borderline platelet count, which, on the other hand, would not contraindicate the endoscopy. Six of the 18 reported patients $(33.3 \%)$ had leukemia or previous bone marrow transplantation, suggesting this as a potential high-risk group. In addition, all three patients who died were leukemic.

The clinical presentation of duodenal hematoma was similar in all cases, consisting more commonly of protracted vomiting and severe abdominal tenderness a few hours after the procedure. Besides causing duodenal obstruction, duodenal hematomas can also occlude the ampulla of Vater, causing acute pancreatitis or obstructive hyperbilirubinemia, and these complications were often associated with the main obstructive picture. Most nonperforated patients were managed conservatively, as is recommended (10). The prognosis for duodenal hematoma itself is excellent, although deaths related to pancreatitis and hyperbilirubinemia have been reported $(7,11)$. Moreover, there appears to be no tendency for bowel perforation or late complications such as the formation of pseudocysts, fistulas or duodenal strictures. However, Hermier et al (12) reported a case of a boy with Noonan's syndrome who presented with chronic pancreatitis two years after having an intramural duodenal hematoma following a capsule jejunal biopsy.

The true incidence of duodenal hematomas after intestinal biopsy is not known, but data suggest that it can be as high as one in 1250 (6). However, specific groups, such as patients with leukemia, previous bone marrow transplantation, low platelet count or otherwise impaired coagulation, may be even more vulnerable to such complication. The cause of duodenal hematomas is not known either. Abnormal coagulation has been clearly implicated in some cases (7-9), and several features of duodenal anatomy may account for the occurrence of intramural hematomas in patients with normal coagulation. The relative immobility of the duodenum, its close position to the lumbar spine and its rich submucosal vascular plexus render it especially vulnerable to bleeding when a shearing force is applied.

The diagnosis of postbiopsy duodenal hematoma should be immediately considered in a patient who presents with heavy vomiting and abdominal tenderness shortly after the procedure. The use of imaging techniques is crucial to establish diagnosis, treatment and prognosis. The most useful techniques are CT, ultrasound imaging and upper gastrointestinal series. Although no comparative studies of their usefulness are available, we consider CT to be the imaging modality of choice in patients with suspected postbiopsy duodenal hematoma, 
TABLE 1

Characteristics of patients with duodenal hematoma after endoscopic biopsy

\begin{tabular}{|c|c|c|c|c|c|c|c|}
\hline Case & Reference & $\begin{array}{c}\text { Age (years)l } \\
\text { Sex }\end{array}$ & Hyperamylasemia & Hyperbilirubinemia & Platelet count & Treatment & $\begin{array}{l}\text { Tospitalization } \\
\text { (days) }\end{array}$ \\
\hline 2 & Ben-Baruch et al (20) & $6 / M$ & No & No & NR & Conservative & 7 \\
\hline 4 & Szajewska et al (22) & $11 / \mathrm{M}$ & No & No & Normal & Conservative & 14 \\
\hline 5 & Karjoo et al (23) & $14 / F$ & Yes & No & $366 \times 10^{9} / \mathrm{L}$ & Conservative & 21 \\
\hline 8 & Lipson et al (9) & $15 / M$ & Yes & Yes & $404 \times 10^{9} / \mathrm{L}$ & Surgical & 28 \\
\hline 9 & & $32 / F^{*}$ & Yes & Yes & $50 \times 10^{9} / \mathrm{L}$ & Surgical & Death \\
\hline 10 & & $11 / \mathrm{M}^{*}$ & No & Yes & $31 \times 10^{9} / \mathrm{L}$ & Conservative & 30 \\
\hline 11 & & $36 / F^{*}$ & No & No & $54 \times 10^{9} / \mathrm{L}$ & Conservative & 11 \\
\hline 12 & Guzman et al (6) & $13 / \mathrm{M}$ & Yes & No & $320 \times 10^{9} / \mathrm{L}$ & Surgical & 12 \\
\hline 16 & Sgouros et al (24) & $32 / \mathrm{M}$ & Yes & No & Normal§ & Conservative & 21 \\
\hline 17 & Lloyd et al (15) & $18 / F$ & Yes & No & Normal & Ultrasound-guided drainage & 24 \\
\hline 18 & $\begin{array}{c}\text { Diniz-Santos et al } \\
\text { (present case) }\end{array}$ & $6 / F$ & Yes & No & $279 \times 10^{9} / \mathrm{L}$ & Conservative & 19 \\
\hline
\end{tabular}

*Leukemic patients who had undergone bone marrow transplantation before endoscopy; ${ }^{\dagger}$ Extensive leukemic infiltrates involving multiple organs were the cause of death; ${ }^{\ddagger}$ Bilirubin-induced encephalopathy precluded surgical approach; § The patient had Noonan’s syndrome, which is associated with abnormal platelet function and factor XI deficiency. F Female; M Male; NR Not reported

because not only does it allow the visualization of the hematoma, but also it rules out or confirms perforation. The main disadvantage of CT is that serial follow-up examinations cannot be performed, to avoid high exposure of the patient to radiation. For that purpose, both MR scans and ultrasound can be used. Although the sonographic appearance of duodenal hematoma is not specific enough to be the method of choice in diagnostic investigation, abdominal sonographies may be valuable in the follow-up of conservatively managed inpatients because of the relatively low cost and lack of exposure of the patient to radiation. Another important disadvantage of ultrasound is its inability to precisely assess the extent of the hematoma, and this is the reason why we chose to assess our patient with an MR scan. Upper gastrointestinal series is also a good diagnostic method in this situation, although it can underestimate the magnitude of the hematoma and cannot evaluate the presence of complications. The lesion is seen as a defined mass or as a diffuse fold thickening in duodenum (stacked coin and coiled spring appearance, respectively).

Once the diagnosis is established and the possibility of bowel perforation is ruled out, conservative management, consisting of duodenal aspiration, total parenteral nutrition, intravenous fluids, symptomatic medication and careful observation, should be started. Although evacuation of the hematoma by laparotomy, gastroenterostomy or another bypass procedure was once the most common therapeutic proceeding, it is recommended that the surgical approach be reserved for those rare patients who present with duodenal perforation or whose obstructive symptoms do not improve after a few weeks of conservative management $(13,14)$. Ultrasound- or CT-guided drainage of the hematoma has been shown to be a reasonable choice for nonperforated patients who do not improve with conservative treatment (15-17); successful laparoscopic drainage has also been reported (18).

Hyperamylasemia was reported in 10 of 18 patients (55.6\%) with duodenal hematoma following endoscopic biopsy. While it is a sign of acute pancreatitis in most cases, it is arguable that the manipulation and obstruction of the bowel could account for such elevations. Indeed, Lloyd et al (15) found no evidence of pancreatitis on CT despite the high amylase concentration presented by their patient. An association with acute pancreatitis has also been reported in approximately $20 \%$ of patients with post-traumatic duodenal hematoma, although direct pancreatic trauma cannot be excluded in those cases (13). Anyway, acute pancreatitis secondary to hematoma-induced ampullary obstruction seems to be more strongly associated with postbiopsy hematoma than with post-traumatic hematoma. Therefore, it may be advisable to sample the duodenum as far as possible from the papilla.

\section{REFERENCES}

1. Masci E, Toti G, Mariani A, et al. Complications of diagnostic and therapeutic ERCP: A prospective multicenter study. Am J Gastroenterol 200;96:417-23.

2. Newcomer MK, Brazer SR. Complications of upper gastrointestinal endoscopy and their management. Gastrointest Endosc Clin N Am 1994:4:551-70.

3. Rothbaum RJ. Complications of pediatric endoscopy. Gastrointest Endosc Clin N Am 1996;6:445-59.

4. Chan MF. Complications of upper gastrointestinal endoscopy. Gastrointest Endosc Clin N Am 1996;6:287-303.

5. Kaufman RA, Towbin R, Babcock DS, et al. Upper abdominal trauma in children: Imaging evaluation. AJR Am J Roentgenol 1984;142:449-60.

6. Guzman C, Bousvaros A, Buonomo C, Nurko S. Intraduodenal hematoma complicating intestinal biopsy: Case reports and review of the literature. Am J Gastroenterol 1998;93:2547-50. 
7. Worynski A, Zimmerman M, Herrmann RP, Forbes GM. Intramural duodenal haematoma following endoscopic biopsy in a bone marrow transplant patient. Aust N Z J Med 1998;28:843-4.

8. Ramakrishna J, Treem WR. Duodenal hematoma as a complication of endoscopic biopsy in pediatric bone marrow transplant recipients.J Pediatr Gastroenterol Nutr 1997;25:426-9.

9. Lipson SA, Perr HA, Koerper MA, Ostroff JW, Snyder JD, Goldstein RB. Intramural duodenal hematoma after endoscopic biopsy in leukemic patients. Gastrointest Endosc 1996;44:620-3.

10. Touloukian R. Protocol for the nonoperative treatment of obstructing intramural duodenal hematoma during childhood. Am J Surg 1983;145:330-4.

11. Sadry F, Hauser H. Fatal pancreatitis secondary to iatrogenic intramural duodenal hematoma: A case report and review of the literature. Gastrointest Radiol 1990;15:296-8.

12. Hermier M, Foasso MF, Louis JJ, Descos B, Fournier P. [Intramural hematoma of the duodenum and chronic pancreatitis after jejunal biopsy.] Arch Fr Pediatr 1984;41:127-9.

13. Jewett TC Jr, Caldarola V, Karp MP, Allen JE, Cooney DR. Intramural hematoma of the duodenum. Arch Surg 1988;123:54-8.

14. Camarero C, Herrera D, Corbaton J, Mingo A, Olivares F, Roldan B. Intramural haematoma of the duodenum following endoscopic biopsy: An unusual complication of non-therapeutic endoscopy in children. Eur J Pediatr 2004;163:418-9.

15. Lloyd GM, Sutton CD, Marshall LJ, Jameson JS. Case of duodenal haematoma treated with ultrasound guided drainage. ANZ J Surg 2004;74:500-1.
16. Aizawa K, Tokuyama H, Yonezawa T, et al. A case of traumatic intramural hematoma of the duodenum effectively treated with ultrasonically guided aspiration drainage and endoscopic balloon catheter dilation. Gastroenterol Jpn 1991;26:218-23.

17. Gullotto C, Paulson EK. CT-guided percutaneous drainage of a duodenal hematoma. AJR Am J Roentgenol 2005;184:231-3.

18. Maemura T, Yamaguchi Y, Yukioka T, Matsuda H, Shimazaki S. Laparoscopic drainage of an intramural duodenal hematoma. J Gastroenterol 1999;34:119-22.

19. Ghishan FK, Werner M, Vieira P, Kuttesch J, DeHaro R. Intramura duodenal hematoma: An unusual complication of endoscopic small bowel biopsy. Am J Gastroenterol 1987;82:368-70.

20. Ben-Baruch D, Powsner E, Cohen M, Dintsman M. Intramural hematoma of duodenum following endoscopic intestinal biopsy. J Pediatr Surg 1987;22:1009-10.

21. Zinelis SA, Hershenson LM, Ennis MF, Boller M, Ismail-Beigi F Intramural duodenal hematoma following upper gastrointestinal endoscopic biopsy. Dig Dis Sci 1989;34:289-91.

22. Szajewska H, Albrecht P, Ziolkowski J, Kubica W. Intramural duodenal hematoma: An unusual complication of duodenal biopsy sampling. J Pediatr Gastroenterol Nutr 1993;16:331-3.

23. Karjoo M, Luisiri A, Silberstein M, Kane RE. Duodenal hematoma and acute pancreatitis after upper gastrointestinal endoscopy. Gastrointest Endosc 1994;40:493-5.

24. Sgouros SN, Karamanolis G, Papadopoulou E, et al. Postbiopsy intramural hematoma of the duodenum in an adult with Noonan's syndrome. J Gastroenterol Hepatol 2004;19:1217-9. 


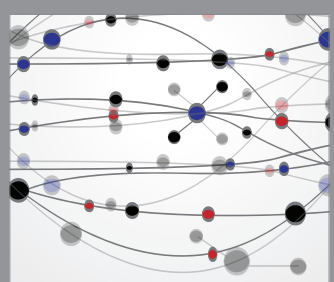

The Scientific World Journal
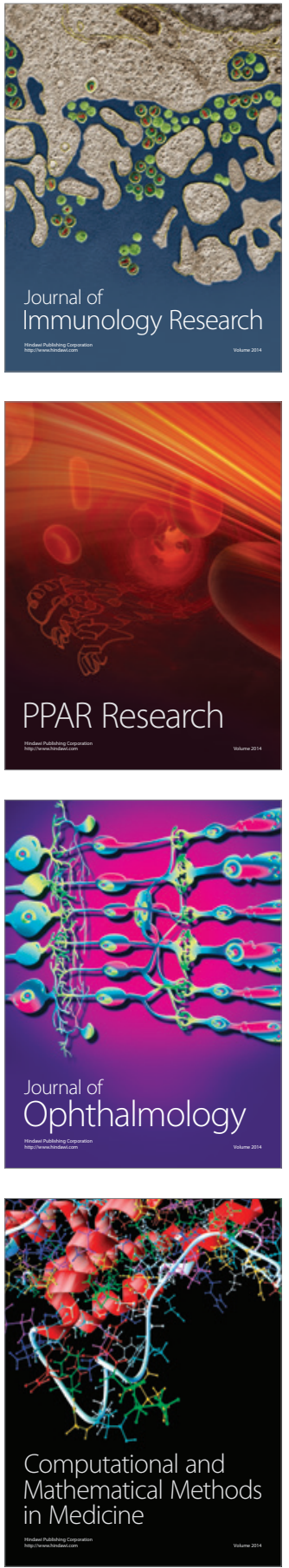

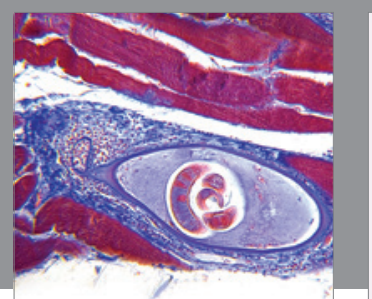

Gastroenterology Research and Practice

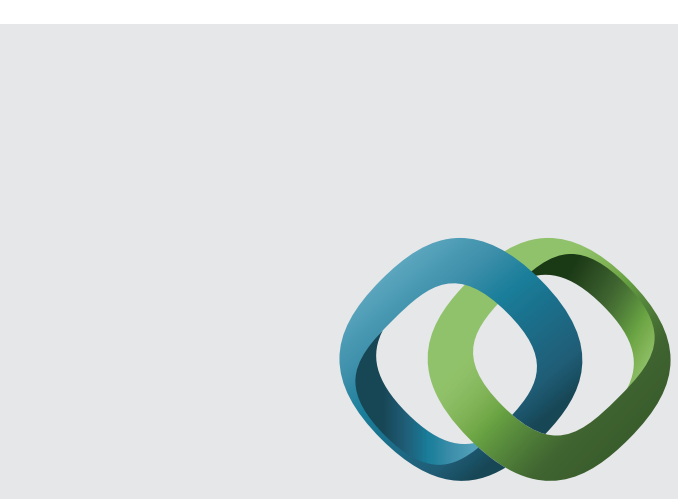

\section{Hindawi}

Submit your manuscripts at

http://www.hindawi.com
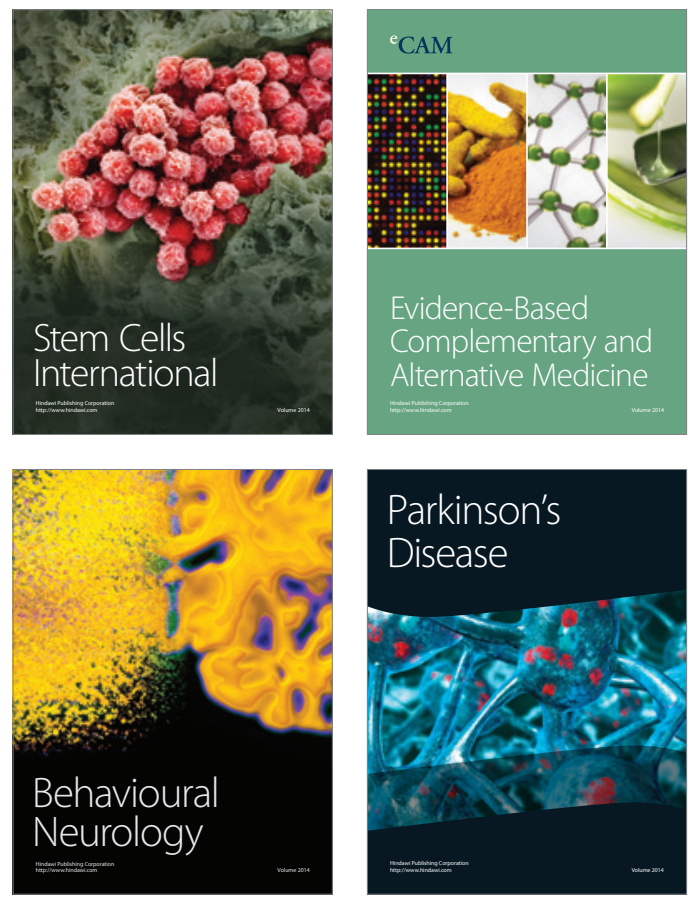
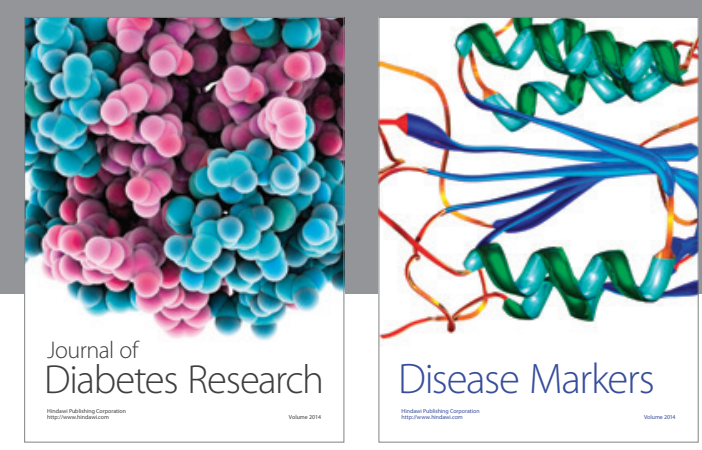

Disease Markers
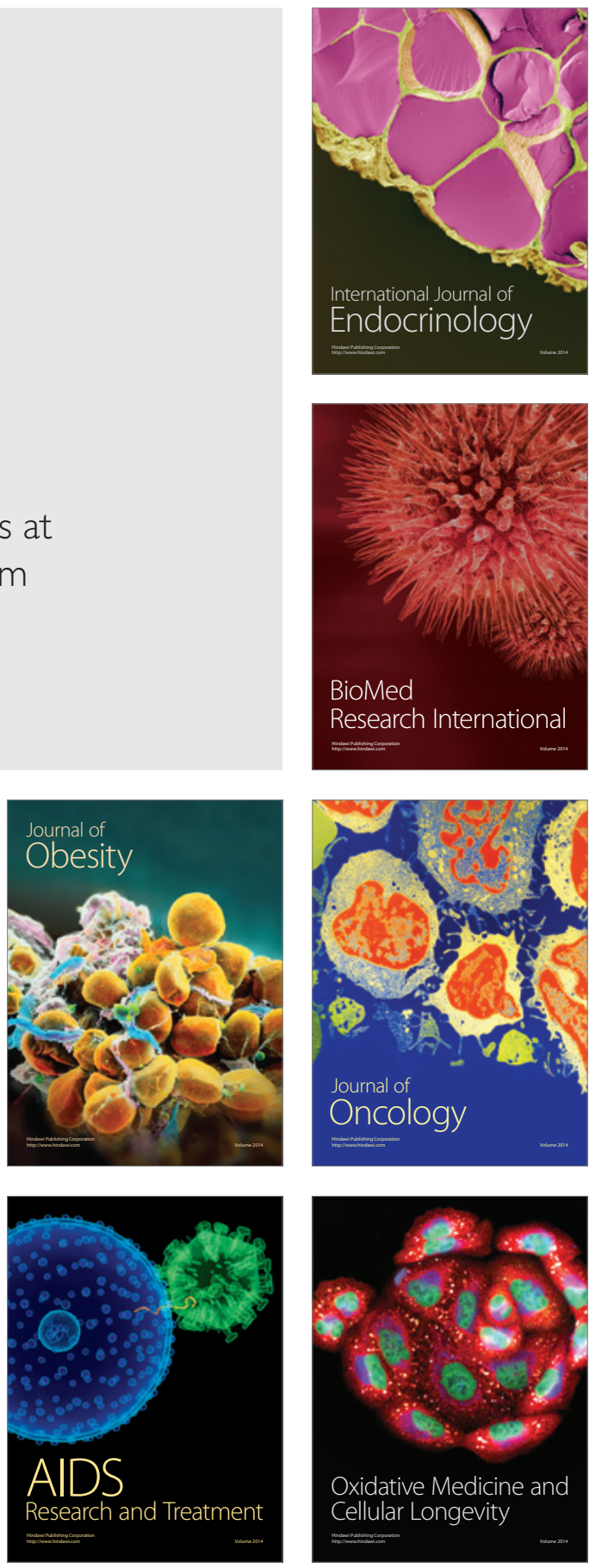